\title{
Enterprise Financial Risk Management Using Information Fusion Technology and Big Data Mining
}

\author{
Huabo Yue, ${ }^{1}$ Haojie Liao $\mathbb{D},{ }^{1,2,3}$ Dong $\mathrm{Li}^{2}$ and Ling Chen ${ }^{3}$ \\ ${ }^{1}$ College of Graduate Studies, Master of Management Program in Management (International Program) WALAILAK University, \\ 222 Thaiburi, Thasala, Nakhon Si Thammarat 80160, Thailand \\ ${ }^{2}$ Accounting and Audit School, Guangxi University of Finance and Economics, Nanning, Guangxi 530003, China \\ ${ }^{3}$ College of Graduate Studies, Bansomdejchaopraya Rajabhat University, Bangkok10600, Thailand
}

Correspondence should be addressed to Haojie Liao; 2017110007@gxufe.edu.cn

Received 29 September 2021; Revised 2 November 2021; Accepted 5 November 2021; Published 15 December 2021

Academic Editor: Chin-Ling Chen

Copyright (c) 2021 Huabo Yue et al. This is an open access article distributed under the Creative Commons Attribution License, which permits unrestricted use, distribution, and reproduction in any medium, provided the original work is properly cited.

\begin{abstract}
This paper aims to study enterprise Financial Risk Management (FRM) through Big Data Mining (BDM) and explore effective FRM solutions by introducing information fusion technology. Specifically, big data technology, Support Vector Machine (SVM), Logistic regression, and information fusion approaches are employedto study the enterprise financial risks indepth.Among them, the selection offinancial risk indexes has a great impact on the monitoring results of the SVM-based FRM model; the Logistic regression-based FRM model can efficientlyclassify financial risks; theinformation fusion-based FRM model uses a fusion algorithm to fuse different information sources. The results show that the SVM-based and Logistic regressionbased FRM models can manage and classify enterprise financial risks effectively in practice, with a classification accuracy of $90.22 \%$ and $90.88 \%$, respectively; by comparison, the information fusion-based FRM modelbeats SVM-based and Logistic regression-based FRM models by presenting a classification accuracy as high as $95.18 \%$. Therefore, it is concluded that the information fusion-based FRM is better than the SVM-based and Logistic regression-based models; it can integrate and calculate multiple enterprise financial risk data from different sources and obtain higher accuracy; besides, big data technology can provide important research methods for enterprise financial risk problems; SVM-based FRM model and Logistic regression-based FRM model can well classify enterprise financial risks, with relatively high accuracy.
\end{abstract}

\section{Introduction}

Today, the fast socio-economic development features a new technological revolutionbyInformation Technology (IT), such as big data [1-3], cloud computing [4-6], and the Internet of Things (IoT), which is transforming people's life, work, and the society towards informatization and intellectualization; moreover, thanks to IT [7-9] and the ecommerce industry based on it, the connection in between people and enterprises is getting ever closer despite their geographic distances and cultural or political barriers. In particular, statistics of the development status of ecommerce enterprisesreveals that financial situation and financial risks [10-12] can determine how far and high an enterprise can develop; thus, the research of these factors has great practical significance. The Big Data Mining
(BDM) approach might be just born to analyze enterprise financial data with its excellent identification effect, thereby being able to give early warning against enterprise financial risks [13-15].

To improve the level of enterprise Financial Risk Management (FRM) [16], scholars have conducted numerous studies and developedsome effective theoretical methods. The financial risk of an entity can be defined as the entity's possibility of money-losing in financial activities. In terms of financial risk theory analysis, there are large numbers of practical cases, some foreign scholars believe that the causes behind the enterprise financial risks are diverse and need specified analysis. Valaskova et al. (2018) [17] once argued that financial risks could be solved by regression analysis. Some experts pointed out that the economic situation was a critical enterprise financial risk factor $[18,19]$. Thereupon, 
some scholars put forward risk minimization, risk transfer, risk tolerance, and risk treatment process to prevent the occurrence of financial risk problems. Zhang et al. (2021) [20] confirmed that big dataand fuzzy Analytic Hierarchy Process (AHP) could efficiently and accurately monitor the financial risks. After studying the enterprise financial risks [21], some scholars believe that enterprise financial risks can be effectively reduced by combining financial risk management with the mathematical model. Domestic scholars also put forward some strategic views and research results, such as using the dynamic portfolio to prevent financial risks. The monitoring and analysis of enterprise financial risk [22-24] ultimately aim to effectively manage the risks. Chinese scholars have established and improved the enterprise internal risk prevention and management system [25-27].

To sum up, the current research on enterprise financial risk has not involved the combination of information fusion and big data technology to study enterprise financial risk. Although there have been attempts on the application of DM to enterprise financial management, they have shown great deficiencies in terms of security and classification accuracy, so there is still much room for improvement. Given these shortcomings, this paper optimizes their deficiencies. Thereupon, three modelsare introduced into Big Data Mining (BDM) to delve into enterprise financial risks: Support Vector Machine (SVM, SVMs)-based FRM model, Logistic regression-based FRM model, and the information fusionbasedFRM model. The innovation of this paper is to combine BDM with the SVM model, Logistic regression model, and information fusion technology, separately to study the enterprise finance risks. Consequently, the combination method can well classify enterprise financial risks, with very high accuracy. The contents provide a theoretical basis for the follow-up research, which is of great significance. It is imperative for enterprises to improve their risk-bearing abilities and promote enterprise development. The technical route of this paper reads1. The proposal of the research direction, namely the enterprise FRM research; 2. Selection of research methods, namely BDM technology, SVM-basedFRM model, Logistic regression-basedFRM model, and information fusion-based FRM model; 3. Research results; 4. Conclusions analysis. Figure 1 shows the technical route.

\section{Monitoring Models under Different Technologies}

2.1. SVM-Based FRM Model. According to the current research on enterprise FRM, financial risk indexes have a great impact on the monitoring results of the SVM-based FRM model. Researchers preferthe business operational financial data as the input index of the FRM model, which shows that enterprise financial data are universal and widely desirable. Therefore, the following indexes are chosen for the proposed enterprise financial risk model: the financial structure of the enterprise, the ratio of retained earnings to total assets, the current debt to assets ratio, the ratio of asset management, and earnings management indexes [28-30]. Figure 2 shows the specific indexes of FRM.
The basic SVM model is a linear classifier with the largest interval in feature space, which can also be extended to a nonlinear classifier by the kernel function method. SVM can be used to classify two-dimensional (2D) patternsandfind the $2 \mathrm{D}$ plane of decision-making in vector spacecompared with perceptron. Both models are classification models. SVM can optimize the hyperplane according to the interval maximization given correctly separable points; whileperceptron strives to find a separation hyperplane that can completely and correctly separate the positive instance points from negative instance points in the training set. That is, under SVMmultiple-pattern identification, the classifier must be built first.

SVM can well addressboth nonlinear classification and linear classification problems and deeply mine relevant data because SVM can segment the non-segmentable linear samples and transform them from low-dimensional space to high-dimensional space to obtain the best segmentation plane. If the training data set of the SVM algorithm is linear in the plane and can be segmented, then its decision function is calculated by Eq. (1):

$$
y_{i}=\omega x+b
$$

In Eq. (1), $\omega$ means weight vector, and B is offset vector. If the training data set of the SVM algorithm is nonlinear in the plane and can also be segmented, then its decision function is shown in Eq. (2):

$$
\begin{gathered}
\min \left(\frac{1}{2} \omega^{T} \omega+C \sum_{i=1}^{N} \delta_{i}\right) \\
y_{i}(\omega x+b) \geq 1-\delta_{i}, \delta_{i} \geq 0, i=1,2, \cdots, N
\end{gathered}
$$

Eq. (3) is a supplement to Eq. (2). In Eq. (2), C is a penalty factor, and the minimum classification error and maximum spacing of positive and negative categories depend on $\mathrm{C} ; \delta_{i}$ denotes a nonnegative relaxation variable. In the SVM-based enterprise FRM model, the enterprise financial data are used as the input vector, and the SVM algorithm model can well classify the enterprise financial risk and further monitor the risks.

2.2. Big Data Technology. Big datacover far beyond the traditional database in terms of data acquisition, data storage, data management, and data analysis. Thus, big data have shown many advantages, such as abundant data information, fast data conversion, rich data types, and low-value density in the data processing. Considering these factors, this paper integrates BDM into enterprise financial analysis. The specific process of data generation, storage, analysis, and application of enterprise structured big data will go through several complicated steps, and the interrelationship between these processes constitutes the big data structure. Generally, algorithm prediction or document consultation processes all involve big data collection, data storage, data processing, and specific application.

Specific enterprise FRM process is divided into three parts: financial risk identification, evaluation, and 


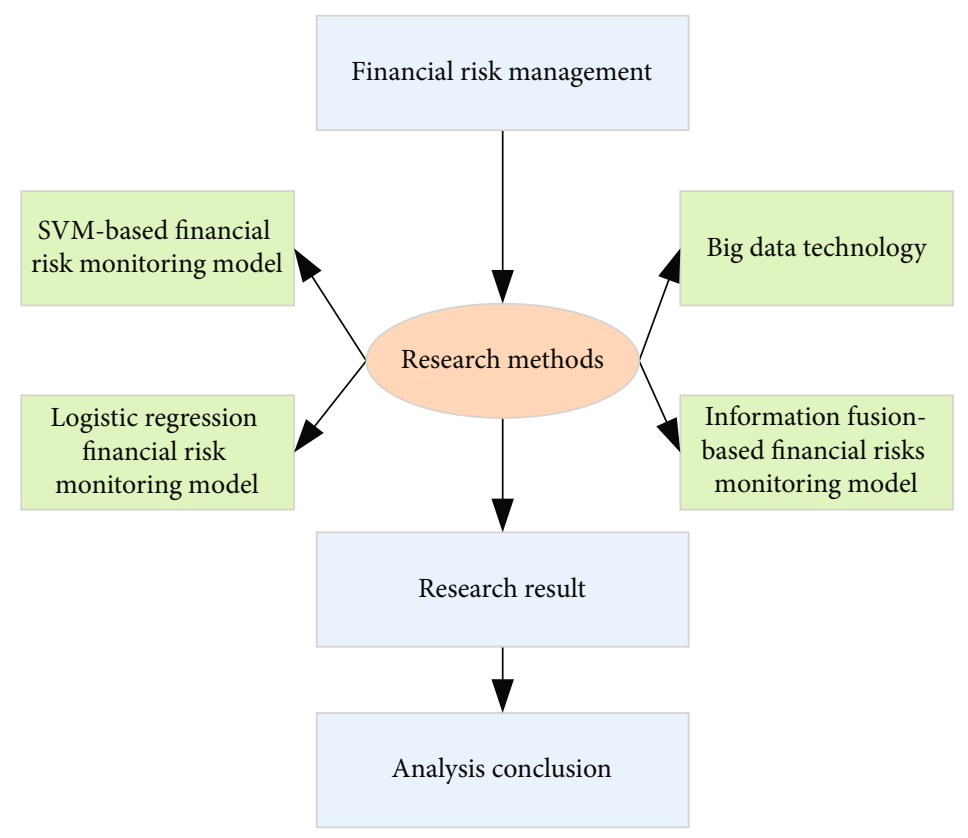

FIgURE 1: Technical route.

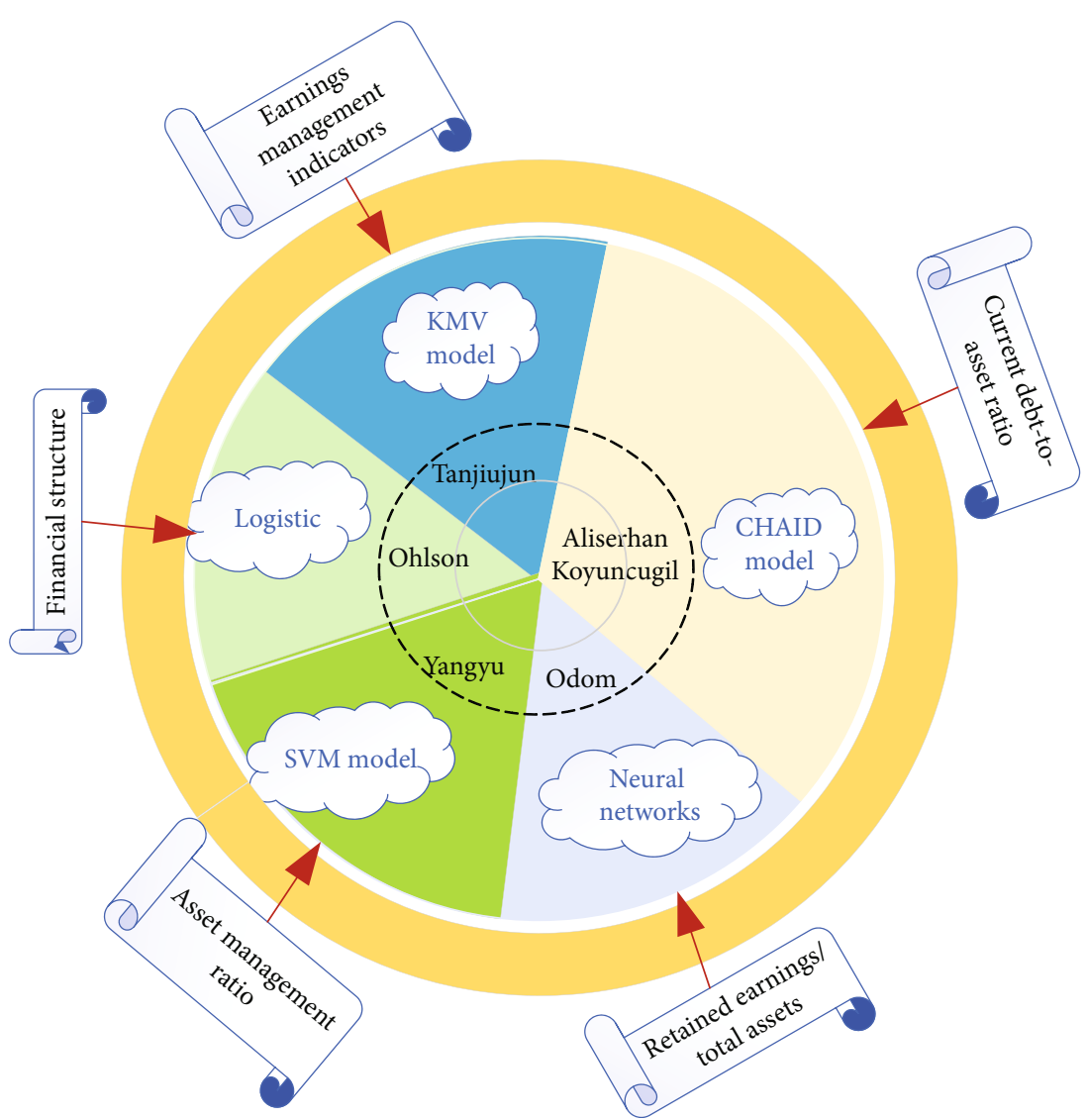

FIgURE 2: FRM indexes. 


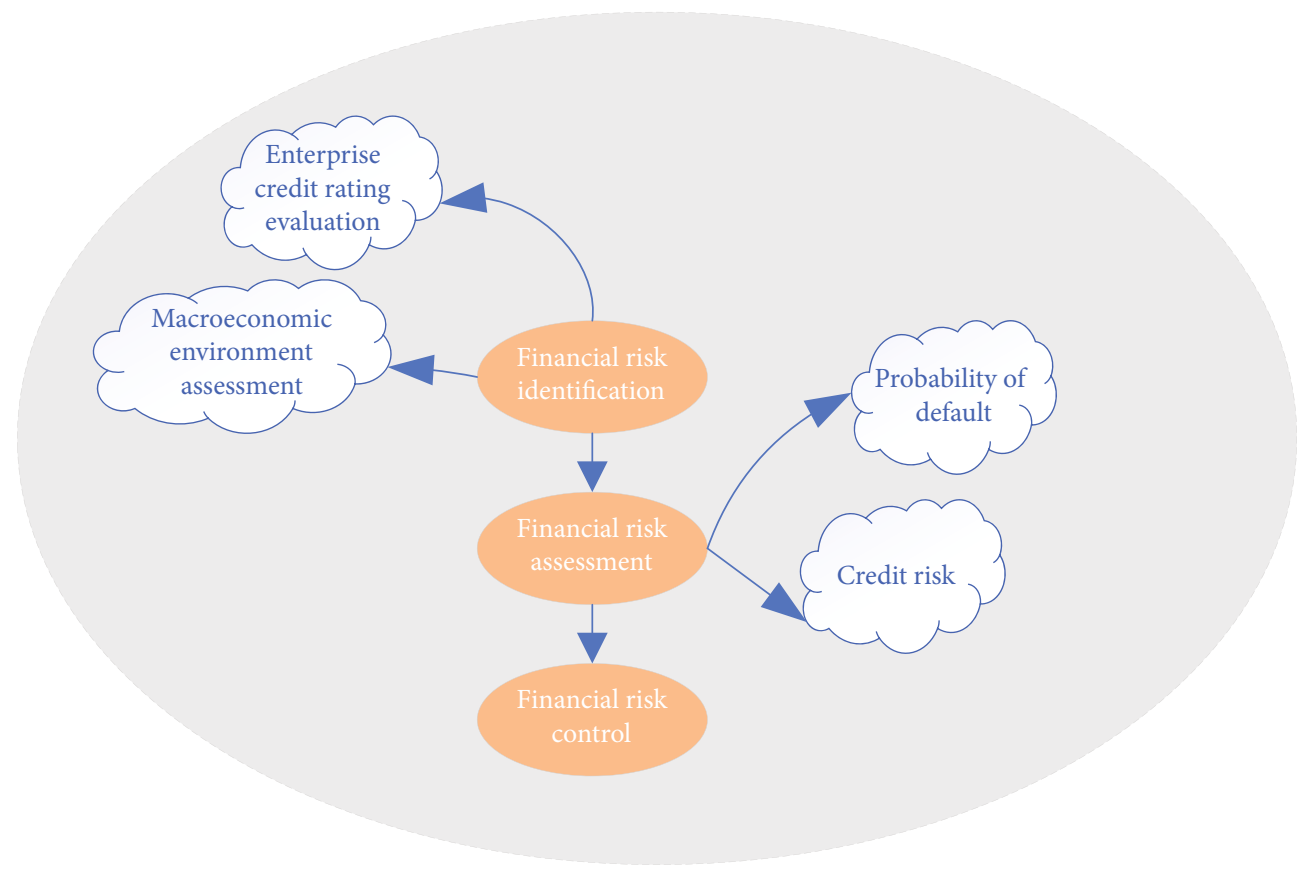

FIGURE 3: Flowchart of enterprise FRM.

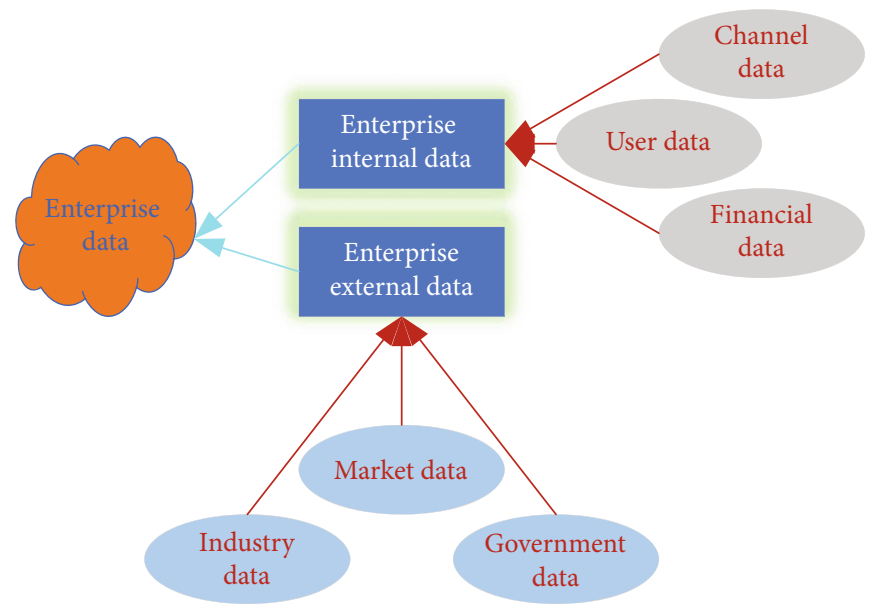

Figure 4: Enterprise data type framework.

management. Further, financial risk identification can be subdivided into the evaluation of the macroeconomic environment and the evaluation of enterprise credit rating; financial risk evaluation can be subdivided into default probability and credit risks. Figure 3 shows the enterpriseFRM process.

The selected enterprise operational general indexes are subdivided: first, the enterprise data can be divided into internal data and external data. Internal data contain channel data, financial data, and user data. External data include market data, government data, and industry data. Figure 4 shows the specific data type framework of the enterprise.

Flow data on the enterprise platform encompass the number of visitors, the length of visit, visitor profile, and visitor-pay conversion. The visitor profile can be subdivided into visitor age, visitor gender, and visitor category. Figure 5

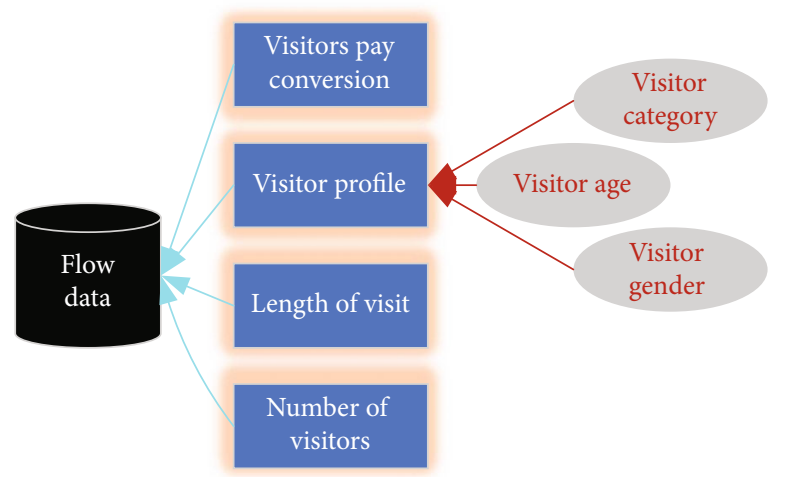

FIgURE 5: Flow data framework of an enterprise platform. 


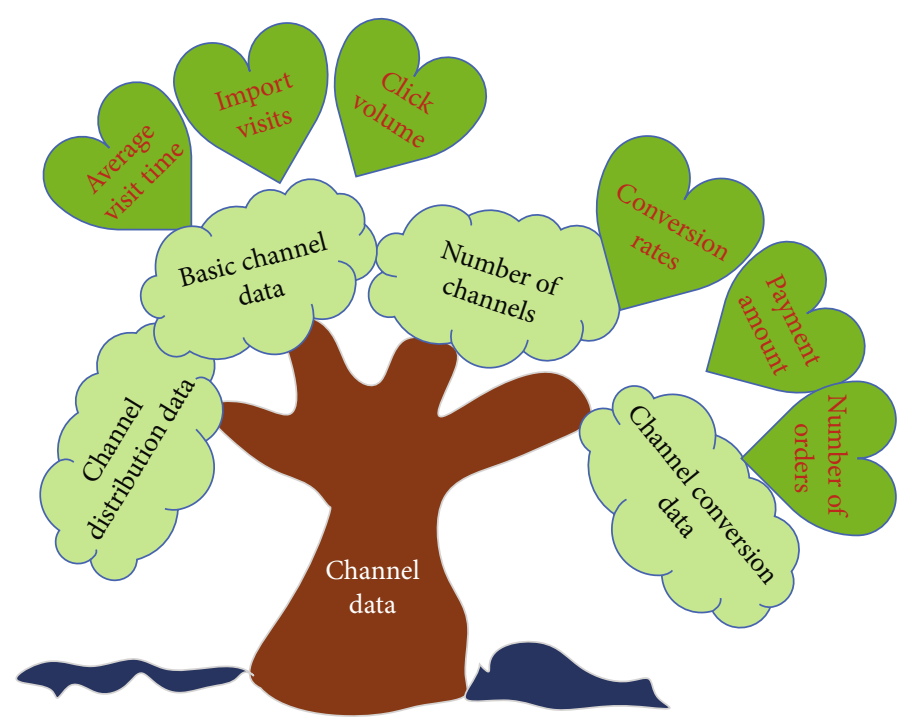

FIGURE 6: Dendrogram of enterprise channel data.

illustrates the flow data framework of the enterprise platform.

Enterprise channel data can be divided into channel distribution data, basic channel data, the number of channels, and channel conversion data. Basic channel data can be subdivided into average visit time, import visits, and click volume. Channel conversion data can be subdivided into conversion rates, the number of orders, and payment amount. Figure 6 presents the channel data tree of the enterprise.

On-platform enterprise data can be divided into four parts: logistics data, visitor transaction data, revenue data, and user data. Figure 7 shows the data framework of onplatform enterprise data.

On-platform business-customer transaction data can be divided into order data, calculated data, and payment data. This division can completely analyze the on-platform customer transaction data and implement it throughout thewhole transaction process. Order data are subdivided into order channel distribution, payment amount, and order amount. Calculated data are subdivided into conversion rates and payment rates. Payment data are subdivided into payment amount, payment types, and payment results. Figure 8 is a dendrogram of on-platform businesscustomer transaction data.

On-platform user data are divided into member user, order user, paying user, and user retention rate. Figure 9 displays the on-platform user data.

Today, many enterprises have established big data analysis platforms to monitor and manage financial risks through big data. The specific plate distribution of analysis model for enterprise big data platform is as follows: first, the model is stratified into data control layer, process scheduling layer, and internal and external structure data layer; second, in terms of local division, the data management platform is divided into data standard, data quality, metadata, and data security; the process scheduling platform isdivided

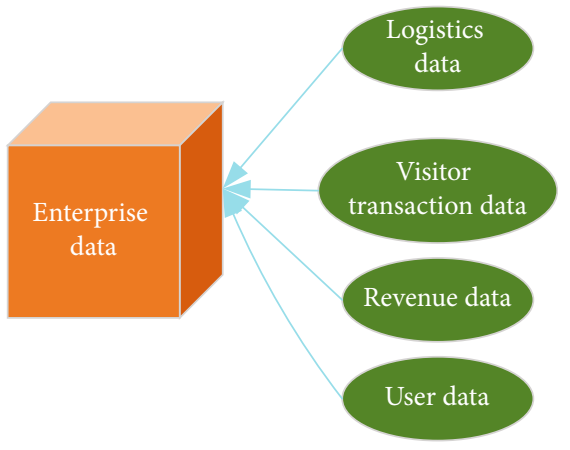

FIGURE 7: Data framework of on-platform enterprises.

into process scheduling, monitoring and warning, and warning model; application data area is divided into user management and risk management; the big data area is divided into the big data to be processed and the big data processed; external enterprise users can be subdivided into business sand table exercise, exercise data area, subject data, and subject data area. The analysis model of enterprise big data platform is shown in Figure 10.

2.3. Logistic Regression-basedFRM Model. Logistic regression and multiple linear regressionare similar and both belong to the generalized linear modelwhile differing inthe dependent variables. The dependent variables of a binomial distribution, namely Logistic regression, can either be dichotomous or multi-classified, in which dichotomous is more commonly used and easier to explain. Thus, binary Logistic regression is most commonly used in practice.

The Logistic regression method can efficiently handle data classification problems and can be used for data monitoring and analysis. The linear regression model can be implemented by the maximum likelihood estimation method under the Logistic regression model so that the data set of binary variables can be classified [31-33]. Figure 11 


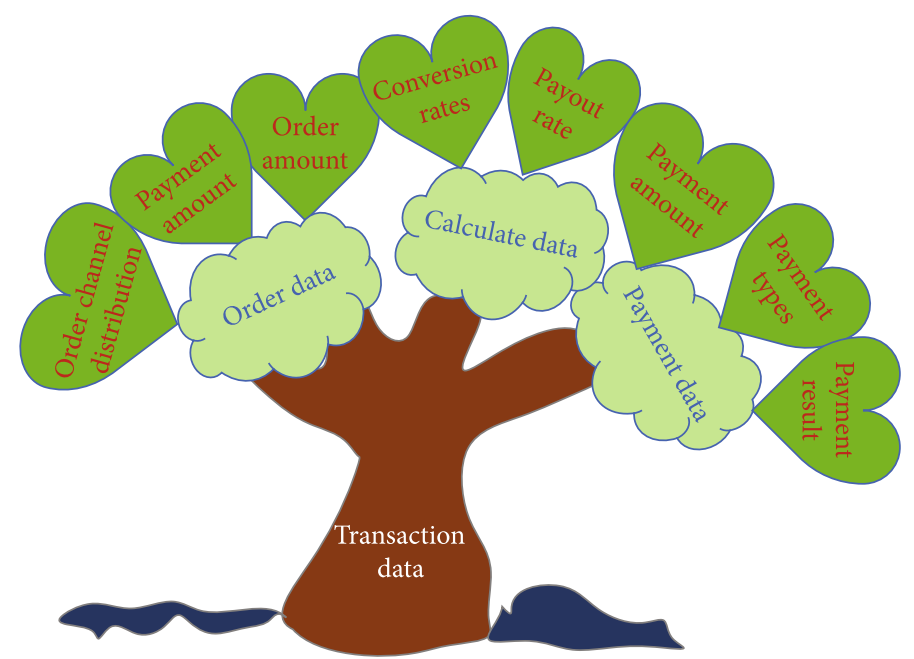

FIGURE 8: Dendrogram of on-platform business-customer transaction data.

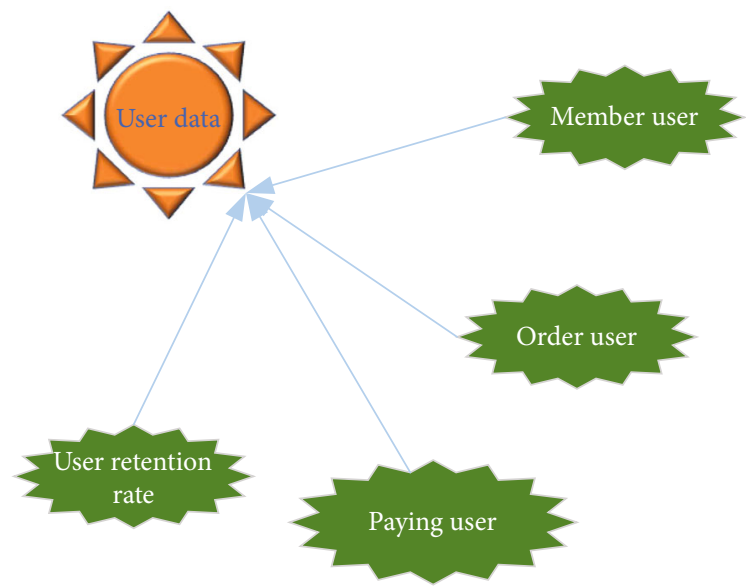

FIGURE 9: On-platform user data framework.

demonstrates the specific financial indexes of the model input data.

The parameters of the Logistic regression model function are set as follows: $x_{i}$ means the interpretation of independent variables, and $y_{i}$ must obey the distribution of Eq. (4):

$$
\begin{gathered}
P\left(y_{i}=1 \mid x_{i}\right)=P\left[\varepsilon_{i} \leq\left(\alpha+\beta x_{i}\right)\right]=\frac{1}{1+e^{\alpha+\beta x_{i}}} \\
\beta=\left(\beta_{0}, \beta_{1}\right)
\end{gathered}
$$

Eq. (5) is the vector $\mathrm{n} \times 1$. $\beta_{0}$ means constant, and $\beta_{1}$ represents a coefficient vector. The enterprise FRM model implemented by the Logistic regression model is shown in Eq. (6):

$$
y_{i}=\operatorname{In}\left(\frac{p_{i}}{1-p_{i}}\right)=\beta_{0}+\beta_{1} x_{1}+\beta_{2} x_{2}+\cdots+\beta_{n} x_{n}
$$

This Regression model can be transformed into Eq. (7) through calculation:

$$
p_{i}=\left(y_{i}=1 \mid X\right)=\frac{1}{1+\exp \left[-\left(\beta_{0}+\beta_{1} x_{1}+\beta_{2} x_{2}+\cdots+\beta_{n} x_{n}\right)\right]}
$$

In Eq. (7), y means monitoring and judgment, and $\mathrm{P}$ refers to probability support for judgment results.

2.4. Information Fusion-Based FRM Model. The information fusion-based FRM model [34-36] uses a fusion algorithm to fuse different information sources. Dempster-Shafer's (DS) evidence theory is a famous information fusion method with good practicability. DS evidence theory can be used to process data from different sources and finally, transformthem into output results. DS evidence theory aims to gain trust. Based on probability, the fusion processing is conducted according to specific rules, and the trust function is particularly important in this process. Thereupon, the framework of the informationfusion-based FRM model is built. Here, it can be assumed that $U$ is a nonempty set composed of multiple elements, which is the proposed framework. Then, the trust structure is set, namely, the Basic Probability Assignment (BPA) function, which can be simplified to an $m$ function. This probability distribution has the characteristics of Eq. (8) and Eq. (9).

$$
U=\left\{U_{1}, U_{2}, \cdots, U_{n}\right\}
$$

$$
m(\varnothing)=0
$$

$$
\sum_{A \subseteq U} m(A)=1
$$




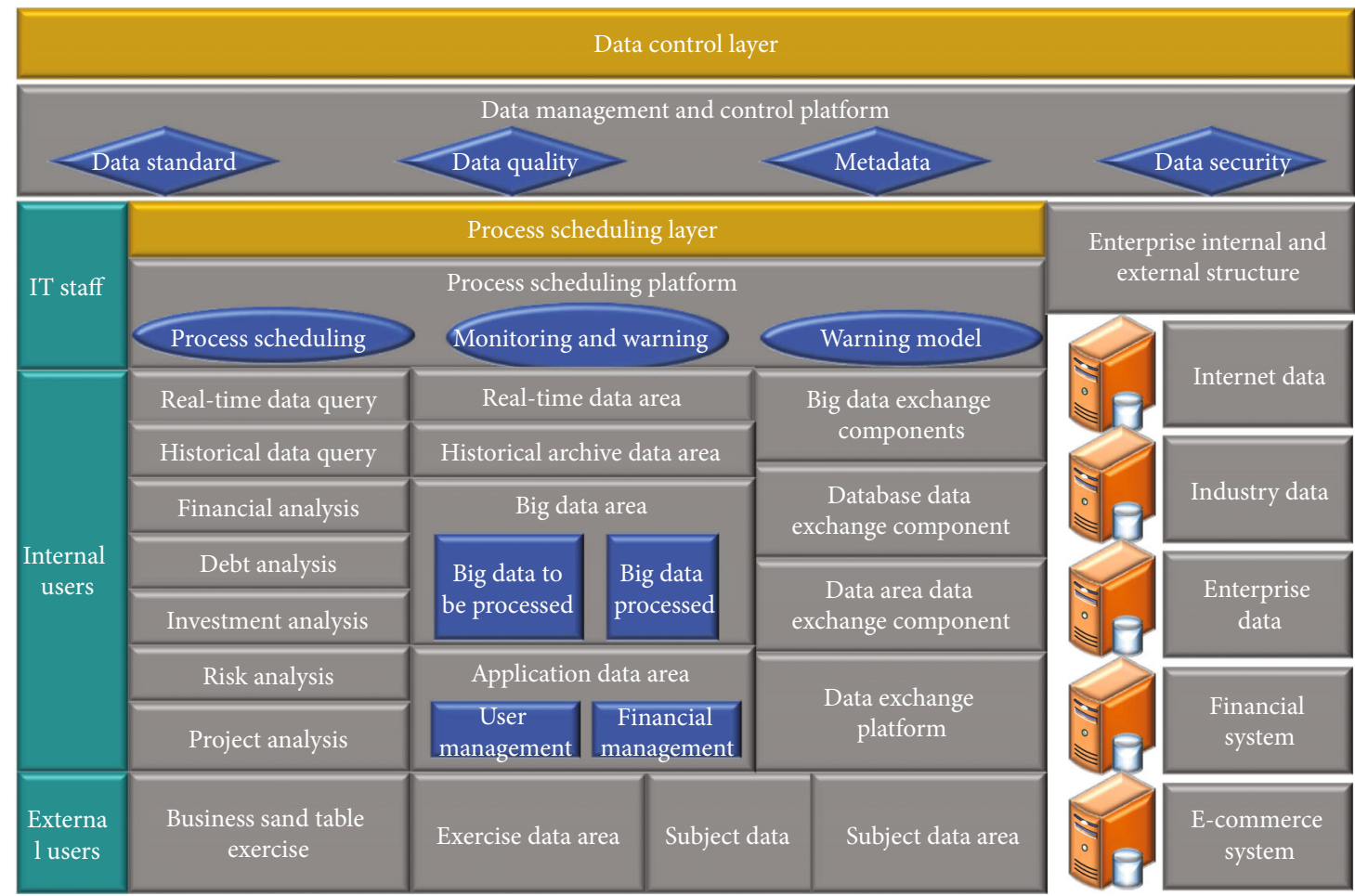

Figure 10: Analysis model for enterprise big data platform.

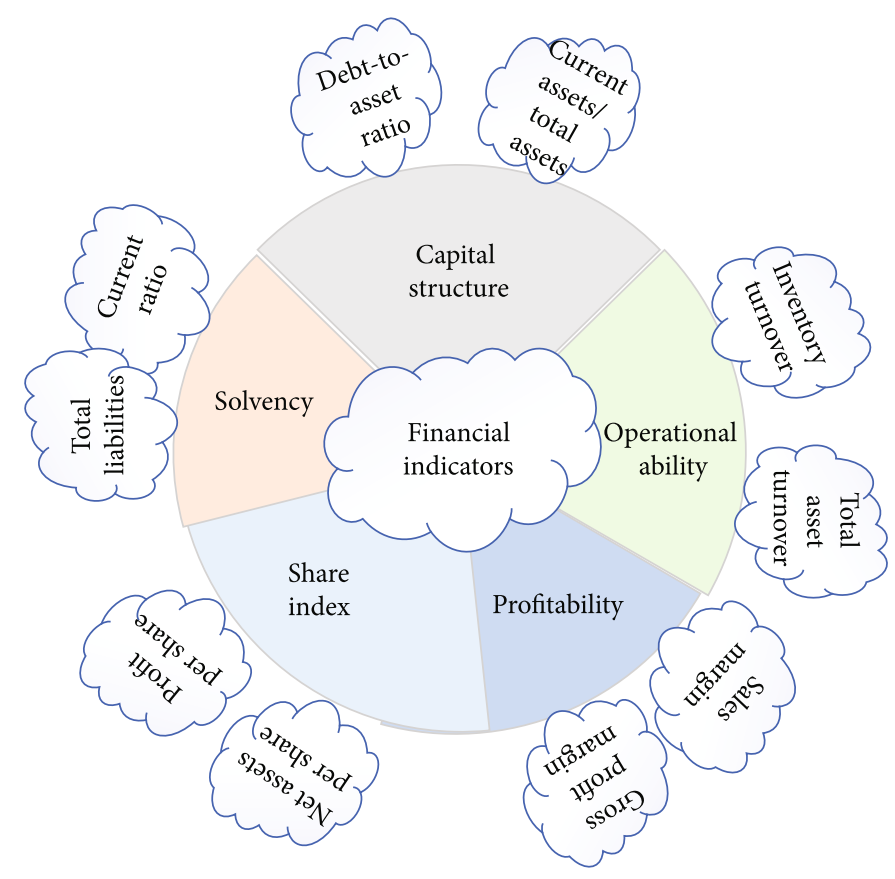

Figure 11: Model indexes. 
Here, the subset of the $U$ set is $A$, then $m(A)$ is the probability distribution function. BeliefFunction (Bel) is calculated by Eq. (11):

$$
\operatorname{Bel}(A)=\sum_{B \subseteq A} m(B)
$$

$\operatorname{Bel}(A)$ isthe expression of A's belief, which represents the reliability function of the $U$ set. In Eq. (12), $m_{1}$ and $m_{2}$ stand for the trust degree of the two reliability functions $B e l_{1}$ and $\mathrm{Bel}_{2}$ based on $\mathrm{U}$ set, respectively. Then, the fusion algorithm can be expressed as Eq. (12):

$$
\begin{gathered}
m(C)=\left\{\begin{array}{l}
\frac{\sum_{A_{i} \cap B_{j}=C} m_{1}\left(A_{i}\right) * m_{2}\left(B_{j}\right)}{1-\sum_{A_{i} \cap B_{j}=\varnothing} m_{1}\left(A_{i}\right) * m_{2}\left(B_{j}\right)}, A \cap B \neq \varnothing \\
0, A \cap B=\varnothing
\end{array}\right. \\
\sum_{A_{i} \cap B_{j}=\varnothing} m_{1}\left(A_{i}\right) * m_{2}\left(B_{j}\right)<1, \forall C \subseteq U, C \neq \varnothing, m(\varnothing)=0
\end{gathered}
$$

Eq. (13) is supplementary to Eq. (12).

$$
K=\sum_{A_{i} \cap B_{j}=\varnothing} m_{1}\left(A_{i}\right) * m_{2}\left(B_{j}\right)
$$

In Eq. (14), K means the degree of conflict between different pieces of evidence. Equation Eq. (15) indicates the probability of classified monitoring.

$$
p=\left(p_{0}, p_{1}\right)
$$

$\mathrm{p}_{0}$ denotes the probability of financial normality under enterprise FRM. $p_{1}$ refers to the enterprise financial risk probability under monitoring.

$$
P_{S V M}=\left(p_{0}, p_{1}\right)
$$

Eq. (16) stands for the probability of the SVM-based FRM model.

$$
P_{\text {logistic }}=\left(p_{0}^{\prime}, p_{1}^{\prime}\right)
$$

Eq. (17) expresses the probability of the Logistic regression-based FRM model.

$$
m(C)=\frac{\sum_{F_{i} \cap F_{j}=C} m_{1}\left(F_{i}\right) * m_{2}\left(F_{j}\right)}{1-\sum_{F_{i} \cap F_{j}=\varnothing} m_{1}\left(F_{i}\right) * m_{2}\left(F_{j}\right)}
$$

Eq. (18) represents the fusion calculation based on DS evidence theory and combined with trust.

$$
\begin{aligned}
& \sum_{F_{i} \cap F_{j}=\varnothing} m_{1}\left(F_{i}\right) * m_{2}\left(F_{j}\right)<1 \\
& \forall C \subseteq U, C \neq \varnothing, m(\varnothing)=0 \\
& m_{1}\left(F_{i}\right)=p_{i}, m_{2}\left(F_{j}\right)=p_{j}^{\prime}
\end{aligned}
$$

Eqs. (19)-(21) are supplements to Eq. (18). To sum up, the trust degree of $\mathrm{m}(\mathrm{C})$ is obtained through the SVM and Logistic regression model. Then, the information fusionbased FRM model is implemented, which can effectively monitor the enterprise financial risk and improve the model reliability; this is of great significance for obtaining the specific situation of enterprise financial risk [37, 38].

\section{Results and Discussion}

3.1. Analysis of Enterprise Financial Risk. Following the investigation of deposits and loans of relevant banks, the relevant conditions of several banks are investigatedto ensure the data authenticity, and the relevant data are summarized in Figure 12, in which the deposit loan ratio is $69.6 \%$ in 2018 , $71.3 \%$ in 2019 , and $72.3 \%$ in 2020 ; the ratio of liquidity in 2018,2019 , and 2020 are $34.2 \%, 34.6 \%$, and $33.8 \%$, respectively; the standard value in 2018, 2019, and 2020 is $25 \%$. Obviously, the deposit loan ratio is increasing yearly from 2018 to 2020, showing that the deposit loan ratio has a great impact on liquidity and potential financial risks. The enterprise liquidity index is shown in Figure 12.

Figure 13 indicates the risk of profitable financing situations: the asset profit margin is $1.66 \%$ in $2018,1.68 \%$ in 2019 , and $1.6 \%$ in 2020 ; the average bank fund is $1.38 \%$ in $2018,1.36 \%$ in 2019 , and $1.3 \%$ in 2020 ; the capital profit margin is $1.16 \%$ in $2018,1.15 \%$ in 2019 , and $1.1 \%$ in 2020 . Apparently, from 2018 to 2020, the capital profit margin has been the lowest, while the asset profit margin has been the highest. The level of capital profit determines the profitability and reflects the enterprise FRM. According to quantitative data analysis, there is a need for enterprises to strengthen their assets to prevent potential financial risks. The enterprise profitability index is shown in Figure 13.

\subsection{Financial Risk Analysis Based on Information Fusion} Technology. This section is divided into two parts according to the sample data. The first part is the test, and the second part is to verify the accuracy of the SVM-based FRM model and Logistic regression-based FRMmodel. In Figure 14, (a) presents the specific financial risk probability of five enterprises under the SVM-based FRM model: the probability of enterprise $1,2,3,4$, and 5 is $0.85,0.95,0.83,0.88$, and 0.93, respectively; (b) showcases specific financial risk probability of five enterprises underLogistic regression-based FRM model: the probability of enterprise 1, 2, 3, 4, and 5 is $0.95,1,0.98,1$, and 0.86 , respectively; (c) displaysspecific financial risk probability of five enterprisesunder information fusion-based FRM model: the probability of enterprise $1,2,3,4$, and 5 is $0.99,1,0.99,1$, and 0.98 , respectively. Figure 14 reveals the monitoring results of different enterprise FRM models.

Figure 15 signifies that the risk classification accuracy under the SVM-based, Logistic regression-based, and information fusion-based FRM modelsare $90.22 \%, 90.88 \%$, and $95.18 \%$, respectively; while the monitoring error rate is $9.68 \%, 9.56 \%$, and $4.68 \%$. Figure 15 shows the comparison of the accuracy and error rate of different enterprise FRM models. 


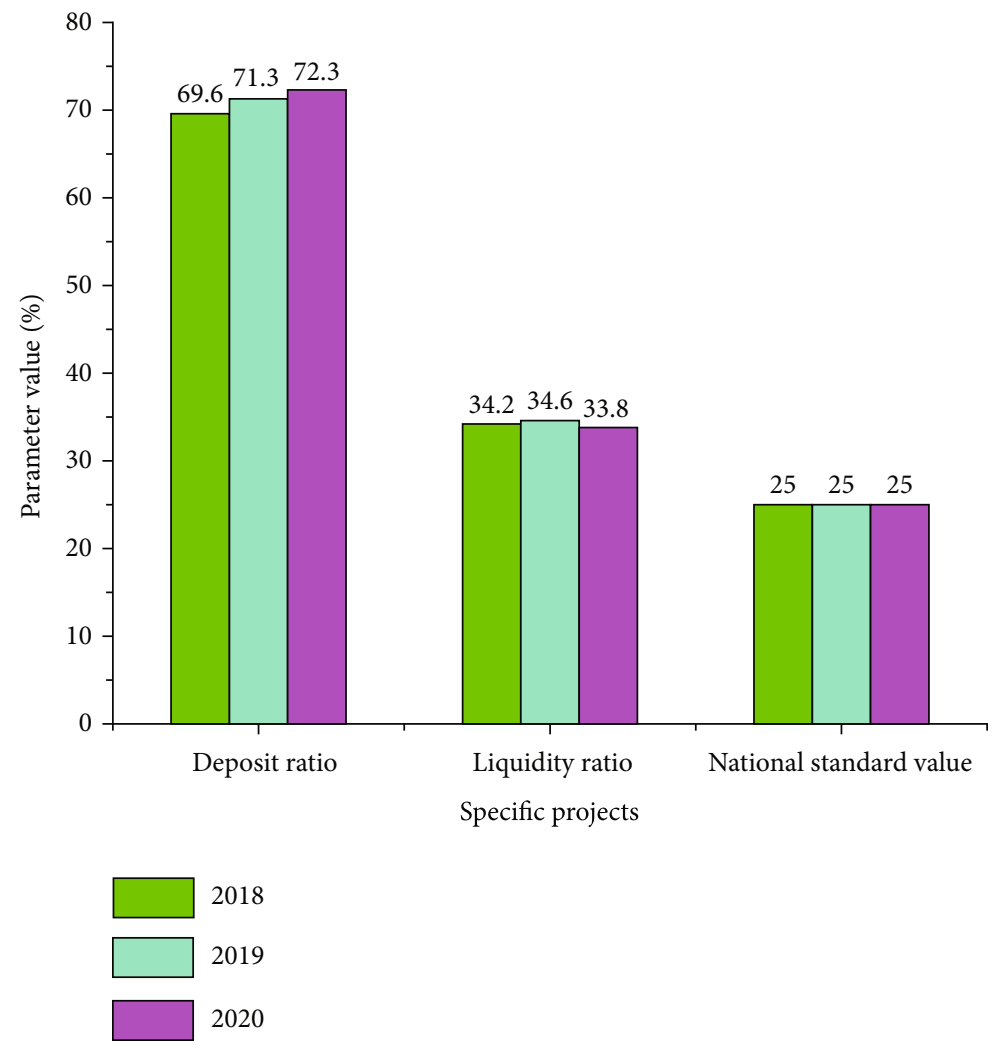

FIgURE 12: Enterprise liquidity index.
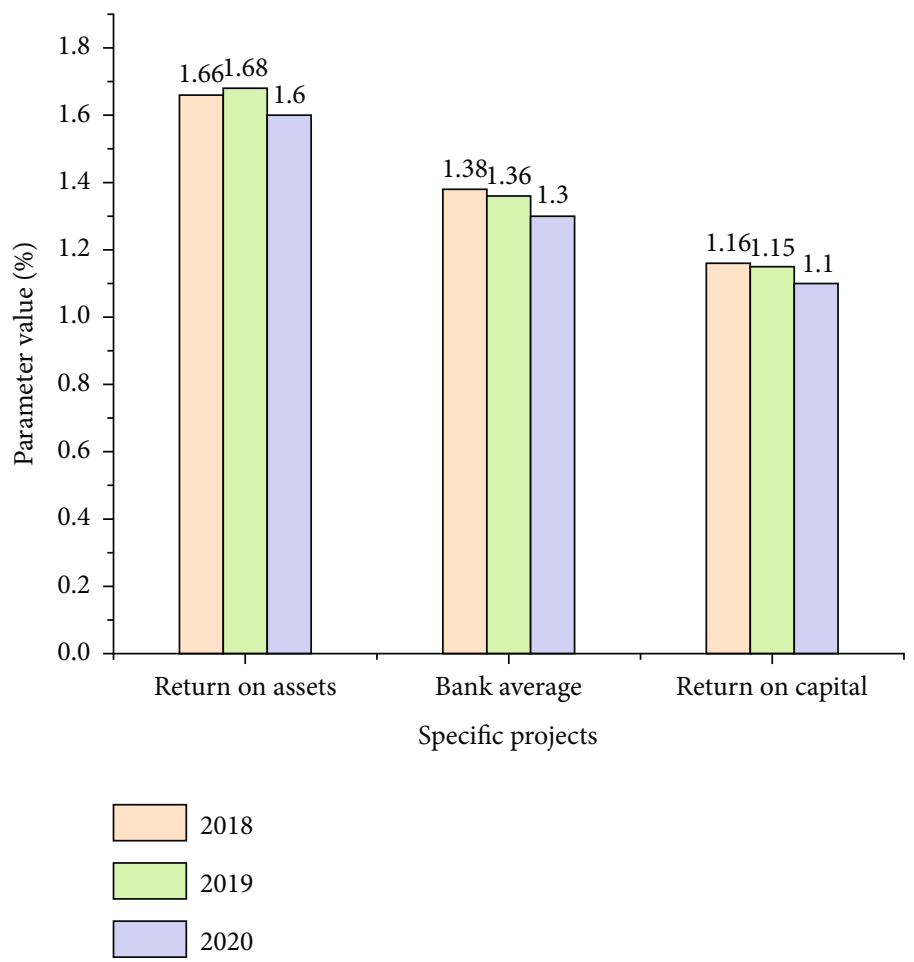

Figure 13: Enterprise profitability index. 


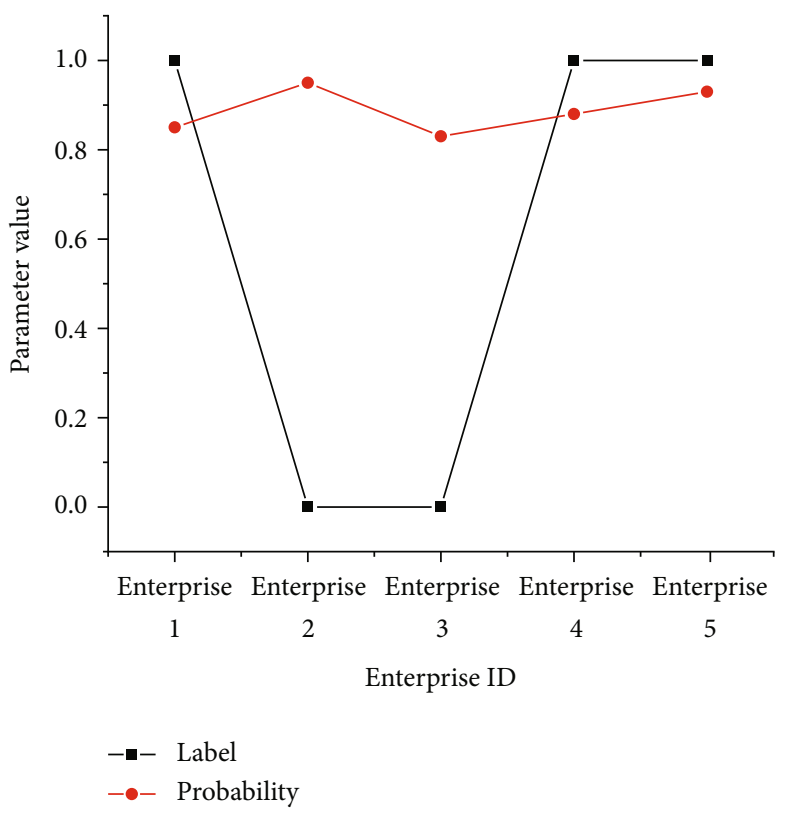

(a)

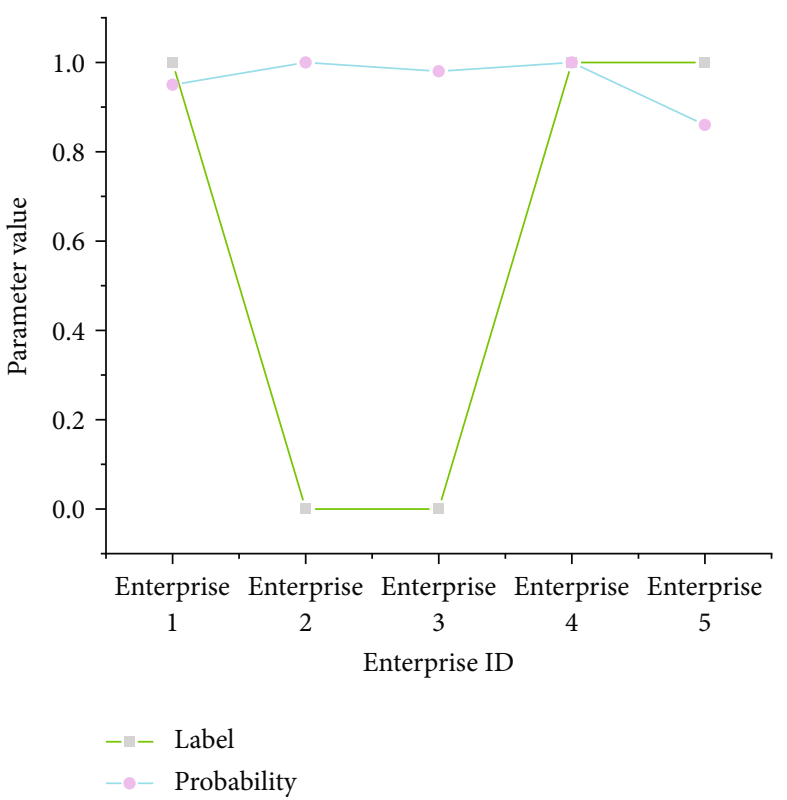

(b)

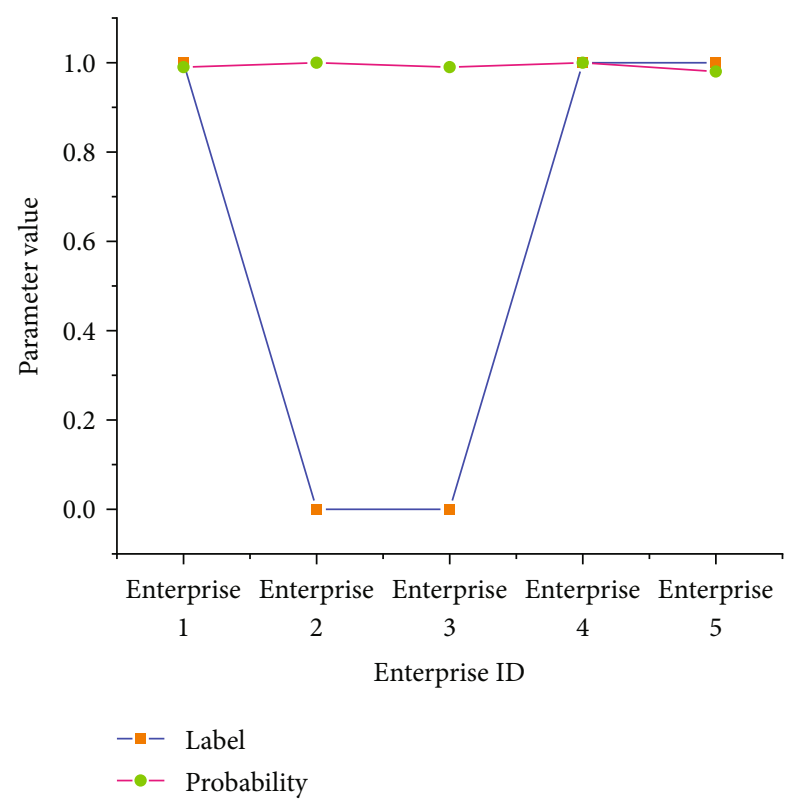

(c)

FIGURE 14: Monitoring results ofdifferent FRM models (a: Result of SVM-based FRM model; b: Result of Logistic regression-based FRM model; c: Results of information fusion-based FRM model).

In Figure 15, the ordinate represents the index value. The specific index value can be obtained through the mapping software. Figures 14 and 15 suggest that the SVM-based FRM model and Logistic regression-based FRM model have shown excellent classification effect for enterprise financial risks with an accuracy of $90.22 \%$ and $90.88 \%$, respectively; by comparison, the information fusion-based FRM modelbeats the SVM-based FRM model and Logistic regressionbased FRM model with an accuracy as high as $95.18 \%$. Thus, the information fusion-based FRM model outperforms the SVM-based FRM model and Logistic regression-based FRM model; it can process and calculate the enterprise financial risk data from different sources and obtain higher accuracy. The analysis of specific data shows that although this paper uses the real-time database to solve the uncertainty in information fusion, the fusion results from the combination of information fusion and BDM technology are still unsatisfactory; thiswill be the research focus in the future.

In summary, the analysis of specific sample data implies that the accuracy of the SVM-based FRM model and Logistic regression-based model in enterprise financial risk classification is relatively high, which are $90.22 \%$ and $90.88 \%$, respectively; by contrast, the classification accuracy of information 


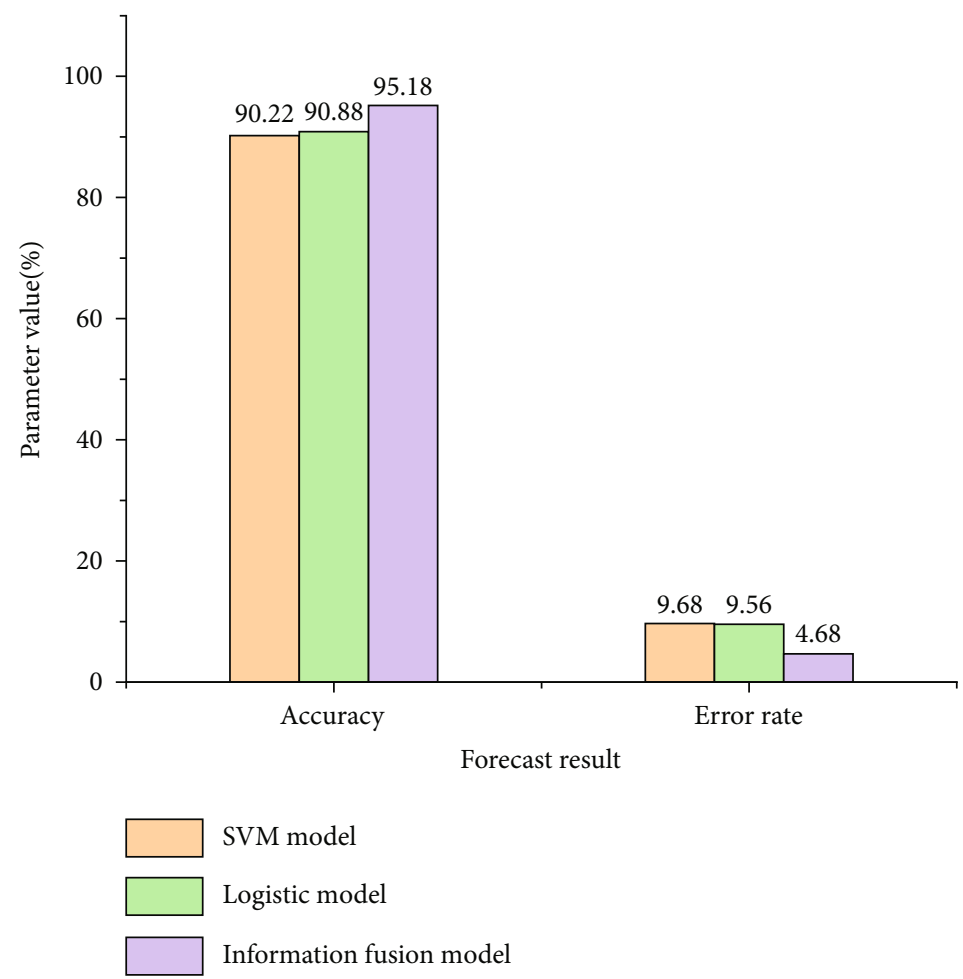

FIgURE 15: Comparisons of accuracy and error rate of enterprise FRM models.

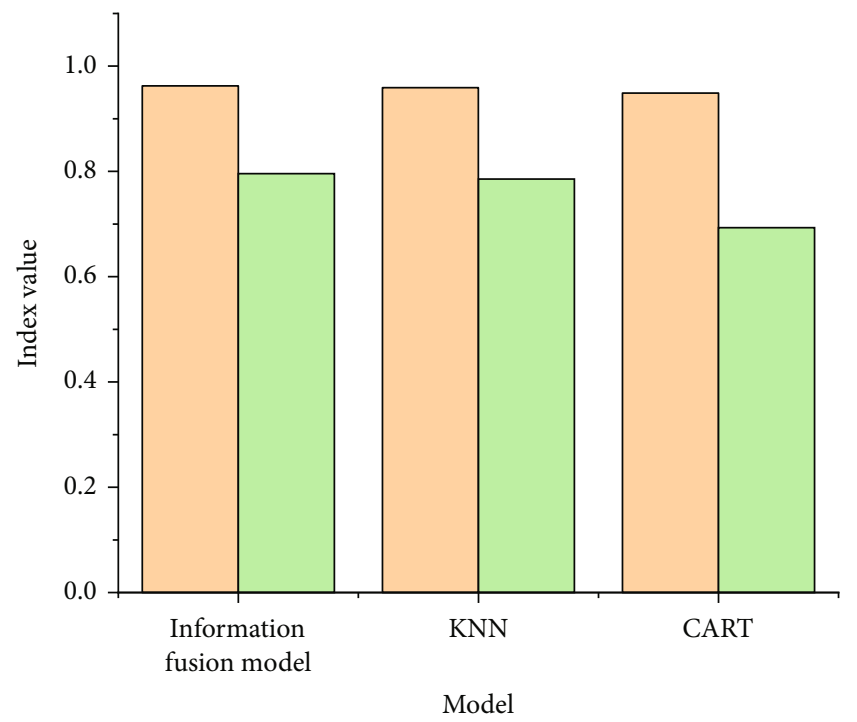

Accuracy

F1

Figure 16: Comparison of Accuracy mean and F1 value of each model.

fusion-basedFRM is significantly higher than SVM-based FRM model and Logistic regression-based FRM model with an accuracy of $95.18 \%$. This shows that the information fusion-based FRM model is better than the SVM-based FRM model and Logistic regression-based FRM model.
Compared with other monitoring and classification models, the actual application effect of the information fusion-based enterprise FRMmodel will be more outstanding and have more obvious advantages.

3.3. Performance Comparison between Information FusionBased FRM Model and Similar Algorithms. This section further verifies the accuracy and classification effect of the proposed information fusion-based FRM model practical application by comparative analysis with K-nearest neighbor (KNN) and Classification And Regression Tree (CART) from Accuracy mean and F1 score. The experimental results are shown in Figure 16.

Figure 6 corroborates that the mean Accuracy and F1 value of the proposed information fusion-based FRM model is 0.9626 and 0.7958 , respectively. Compared with $\mathrm{KNN}$ and CART models, the proposed information fusion-based FRM model has better practical applicability, a more prominent risk prediction effect, and can provide good algorithm support for enterprise FRM.

\section{Conclusion}

The advancement of science and technology, especially, state-of-art technologies, innovates people's lives while bringing challenges at the same time. Likewise, the rapid development and growth of enterprisesare also followed byvarious financial risks. Aiming at the current situation of enterprise financial risk, this paper makesan in-depth study on enterprise financial risk based on BDM, SVM, Logistic regression, and information fusion technology. The 
following conclusions are drawn: big data technology can provide important research methods for enterprise financial risk problems. SVM-based FRM model and Logistic regression-based FRM model can well classify enterprise financial risks with high accuracy; the information fusionbased FRM model can further improve the classification accuracy of enterprise financial risks and shows high reliability and effectiveness; additionally, different enterprise risk indexes are analyzed, finding that there is a need for enterprises to strengthenFRMunder big data, especially, the management of liquidity and profitability indexes. The shortcomings of this paper are summarized: although the proposed information fusion-based FRM model improves the classification accuracy of enterprise financial risks; but its accuracy might be able to get a higher level in future research. The follow-up research will further improve the enterprise FRMperformance based on the drawn conclusions.

\section{Data Availability}

The labeled dataset used to support the findings of this study is available from the corresponding author upon request.

\section{Conflicts of Interest}

The authors declare no competing interests.

\section{Acknowledgments}

Phase results of 2021 Guangxi Education Science Planning Funding Key Project (2021A038); Stage results of 2019 Guangxi Higher Education Undergraduate Teaching Reform Project Key Topic (2019JGZ145); 2018 National Social Science Foundation of China (18BJY015); 2018 Academic Research Project of Master of Taxation (SWX20180010); Phase results of the Integration Innovation Project (2020JGA166) of Guangxi University for Nationalities in 2020; 2015 China-ASEAN Economic and Trade Development and South China Sea Strategic Collaborative Innovation Center Project (15\&YBB06).

\section{References}

[1] D. Blazquez and J. Domenech, "Big data sources and methods for social and economic analyses," Technological Forecasting and Social Change, vol. 130, pp. 99-113, 2018.

[2] M. K. Saggi and S. Jain, "A survey towards an integration of big data analytics to big insights for value-creation," Information Processing \& Management, vol. 54, no. 5, pp. 758-790, 2018.

[3] A. Oussous, F. Z. Benjelloun, A. Ait Lahcen, and S. Belfkih, "Big data technologies: a survey," Journal of King Saud University-Computer and Information Sciences, vol. 30, no. 4, pp. 431-448, 2018.

[4] M. Abdel-Basset, M. Mohamed, and V. Chang, "NMCDA: a framework for evaluating cloud computing services," Future Generation Computer Systems, vol. 86, pp. 12-29, 2018.

[5] B. Varghese and R. Buyya, "Next generation cloud computing: New trends and research directions," Future Generation Computer Systems, vol. 79, pp. 849-861, 2018.
[6] C. Stergiou, K. E. Psannis, B. G. Kim, and B. Gupta, "Secure integration of IoT and cloud computing," Future Generation Computer Systems, vol. 78, pp. 964-975, 2018.

[7] S. Park, G. J. Choi, and H. Ko, "Information technology-based tracing strategy in response to COVID-19 in South Korea-privacy controversies," JAMA, vol. 323 , no. 21, pp. 21292130, 2020.

[8] M. S. Rad, M. Nilashi, and H. M. Dahlan, "Information technology adoption: a review of the literature and classification," Universal Access in the Information Society, vol. 17, no. 2, pp. 361-390, 2018.

[9] J. Benitez, G. Ray, and J. Henseler, "Impact of information technology infrastructure flexibility on mergers and acquisitions," MIS Quarterly, vol. 42, no. 1, pp. 25-43, 2018.

[10] Pavlo Tychyna Uman State Pedagogical University, Ukraine, I. Korol, A. Poltorak, and Mykolayiv National Agrarian University, Ukraine, "Financial risk management as a strategic direction for improving the level of economic security of the state," Baltic Journal of Economic Studies, vol. 4, no. 1, pp. 235-241, 2018.

[11] K. Valaskova, T. Kliestik, L. Svabova, and P. Adamko, "Financial risk measurement and prediction Modelling for sustainable development of business entities using regression analysis," Sustainability, vol. 10, no. 7, p. 2144, 2018.

[12] A. Kim, Y. Yang, S. Lessmann, T. Ma, M. C. Sung, and J. E. V. Johnson, "Can deep learning predict risky retail investors? A case study in financial risk behavior forecasting," European Journal of Operational Research, vol. 283, no. 1, pp. 217-234, 2020.

[13] Q. Yang, Y. Wang, and Y. Ren, "Research on financial risk management model of internet supply chain based on data science," Cognitive Systems Research, vol. 56, pp. 50-55, 2019.

[14] C. Brooks, I. Sangiorgi, C. Hillenbrand, and K. Money, "Experience wears the trousers: exploring gender and attitude to financial risk," Journal of Economic Behavior \& Organization, vol. 163, pp. 483-515, 2019.

[15] L. Nguyen, G. Gallery, and C. Newton, "The joint influence of financial risk perception and risk tolerance on individual investment decision-making," Accounting \& Finance, vol. 59, Supplement 1, pp. 747-771, 2019.

[16] C. Sathyamoorthi, M. Mapharing, M. Mphoeng, and M. Dzimiri, "Impact of financial risk management practices on financial performance: evidence from commercial banks in Botswana," Applied Finance and Accounting, vol. 6, no. 1, pp. 25-39, 2020.

[17] K. Valaskova, T. Kliestik, and M. Kovacova, "Management of financial risks in Slovak enterprises using regression analysis," Oeconomia Copernicana, vol. 9, no. 1, pp. 105-121, 2018.

[18] B. J. Ali and M. S. Oudat, "Financial risk, and the financial performance in listed commercial and investment banks in Bahrain bourse," International Journal of Innovation, Creativity and Change, vol. 13, no. 12, pp. 160-180, 2020.

[19] K. W. Lee, "The usage of derivatives in corporate financial risk management and firm performance," International Journal of Business, vol. 24, no. 2, pp. 113-131, 2019.

[20] H. Zhang, A. Khurshid, W. A. Xinyu, and A. M. Băltățeanu, "Corporate financial risk assessment and role of big data; new perspective using fuzzy analytic hierarchy process," Journal for Economic Forecasting, vol. 2, pp. 181-199, 2021.

[21] R. Myšková and P. Hájek, "Mining risk-related sentiment in corporate annual reports and its effect on financial 
performance," Technological and Economic Development of Economy, vol. 26, no. 6, pp. 1422-1443, 2020.

[22] A. Alshehhi, H. Nobanee, and N. Khare, "The impact of sustainability practices on corporate financial performance: literature trends and future research potential," Sustainability, vol. 10, no. 2, p. 494, 2018.

[23] R. Oduro, M. A. Asiedu, and S. G. Gadzo, "Impact of credit risk on corporate financial performance: evidence from listed banks on the Ghana stock exchange," Journal of Economics and International Finance, vol. 11, no. 1, pp. 1-14, 2019.

[24] J. Xie, W. Nozawa, M. Yagi, H. Fujii, and S. Managi, "Do environmental, social, and governance activities improve corporate financial performance?," Business Strategy and the Environment, vol. 28, no. 2, pp. 286-300, 2019.

[25] N. Mselmi, T. Hamza, A. Lahiani, and M. Shahbaz, "Pricing corporate financial distress: empirical evidence from the French stock market," Journal of International Money and Finance, vol. 96, pp. 13-27, 2019.

[26] S. K. Y. Augustine, "The effect of financial risk and environmental risk on mining company performance with good corporate governance as moderating variables," Risk, vol. 11, no. 11, 2019.

[27] J. Oláh, S. Kovács, Z. Virglerova, Z. Lakner, M. Kovacova, and J. Popp, "Analysis and comparison of economic and financial risk sources in SMEs of the Visegrad group and Serbia," Sustainability, vol. 11, no. 7, p. 1853, 2019.

[28] J. S. Raj and J. V. Ananthi, "Recurrent neural networks and nonlinear prediction in SVMs," Journal of Soft Computing Paradigm (JSCP), vol. 1, no. 1, pp. 33-40, 2019.

[29] J. Xu, C. Xu, B. Zou, Y. Y. Tang, J. Peng, and X. You, "New incremental learning algorithm with SVMs," IEEE Transactions on Systems, Man, and Cybernetics: Systems, vol. 49, no. 11, pp. 2230-2241, 2019.

[30] B. Ghaddar and J. Naoum-Sawaya, "High dimensional data classification and feature selection using support vector machines," European Journal of Operational Research, vol. 265, no. 3, pp. 993-1004, 2018.

[31] C. Y. J. Peng, K. L. Lee, and G. M. Ingersoll, “An introduction to logistic regression analysis and reporting," The Journal of Educational Research, vol. 96, no. 1, pp. 3-14, 2002.

[32] C. Mood, "Logistic regression: why we cannot do what we think we can do, and what we can do about it," European Sociological Review, vol. 26, no. 1, pp. 67-82, 2010.

[33] S. J. Press and S. Wilson, "Choosing between logistic regression and discriminant analysis," Journal of the American Statistical Association, vol. 73, no. 364, pp. 699-705, 1978.

[34] Z. Duan, T. Wu, S. Guo, T. Shao, R. Malekian, and Z. Li, "Development and trend of condition monitoring and fault diagnosis of multi-sensors information fusion for rolling bearings: a review," The International Journal of Advanced Manufacturing Technology, vol. 96, no. 1-4, pp. 803-819, 2018.

[35] L. Zhou, C. Zhang, Z. Qiu, and Y. He, "Information fusion of emerging non-destructive analytical techniques for food quality authentication: a survey," TrAC Trends in Analytical Chemistry, vol. 127, article 115901, 2020.

[36] Q. Tian, J. Jia, and C. Hou, "Research on fingerprint identification of wireless devices based on information fusion," Mobile Networks and Applications, vol. 25, no. 6, pp. 2359-2366, 2020.
[37] Y. Gong, X. Su, H. Qian, and N. Yang, "Research on fault diagnosis methods for the reactor coolant system of nuclear power plant based on D-S evidence theory," Annals of Nuclear Energy, vol. 112, pp. 395-399, 2018.

[38] Q. Zhao, S. Wang, K. Wang, and B. Huang, "Multi-objective optimal allocation of distributed generations under uncertainty based on D-S evidence theory and affine arithmetic," International Journal of Electrical Power \& Energy Systems, vol. 112, pp. 70-82, 2019. 